\title{
Towards a Framework of IT Offshore Outsourcing in Small and Medium-sized Enterprises
}

\begin{abstract}
The objectives of this paper are to define and understand the phenomenon of IT offshore outsourcing; to ascertain the principal issues with IT offshore outsourcing and identify trends in current academic thinking; to identify gaps in current academic research on IT offshore outsourcing and do develop models or hypotheses to measure the impact of this change on a small business.
\end{abstract}

Keywords-information technology; offshore outsourcing; small and medium-sized enterprises; culture; organisational change

\section{INTRODUCTION}

Offshore outsourcing of IT business projects has been growing since the late nineties; therefore it is a relatively new area of academic research [1]. Once the preserve of large, multi-national corporations the latest entrant to IT offshore outsourcing is the small and medium sized enterprises (SMEs). Whilst there are numerous academic studies on offshore IT outsourcing, and it has been examined from a variety of approaches, there is a relative scarcity of literature on the subject. The applicability of existing studies to the small business sector is not total, since a small business is not a large enterprise in miniature [3].

\section{LITERATURE REVIEW}

\section{A. Offshore IT Outsourcing}

Offshore outsourcing is defined as "the process of sourcing any business task, process, or function supporting domestic and global operations from abroad, in particular from lower cost emerging economies[...] [5]. The key differentiator is the phrase "from abroad": services are being provided from another jurisdiction.

The scarcity of necessary skills as described in the above example is a commonly cited reason by case study candidates in the literature to look offshore when considering outsourcing IT functions, however the principal driver of offshore outsourcing is usually economic (e.g. [6]). Skilled labour is cheaper in the offshore outsourcing destinations.

Access to a large pool of highly qualified personnel at a fraction of the domestic price is perceived as the major benefit of offshore outsourcing to the client organisation. It is not the only advantage conferred by the arrangement. Quality improvement and innovation are key benefits that may also be gained from offshoring (e.g. [7]).

Offshoring is not without its challenges. The cost benefit can be offset by the high transaction costs of procuring suppliers and overseeing offshore work [8]. There are also risks inherent in dealing with another country where the laws are different and the protection afforded to data and intellectual property by the regulatory environment is not as rigorous. These could be a risk of compliance breaches. Reference [9] highlights the issues of political instability and socio-economic conditions and the challenges these present. It requires careful consideration by the client of project type and scope and the practices of the client organisation [10]. The literary sources agree that cultural difference is another major aspect of IT offshore outsourcing which requires careful consideration as it can threaten to derail a project if not actively managed (e.g. [12])

\section{B. Cultural impacts on offshore IT outsourcing}

Cultural difference has been defined as "the extent to which the members of two distinct groups differ on one or more cultural dimensions, shared values, norms, beliefs and assumptions that help them organise and structure the world" [11]. This implies the greater the culture differences at national level of the outsourcing partners, the "lesser likelihood of outsourcing success". Success, therefore, relies greatly on the effective management of cultural differences [13].

The central question of culture that this paper seeks to answer is: How does a small company manage cultural differences in IT offshore outsourcing? How do small companies equip themselves to manage this aspect and prevent some of the detrimental effects associated with cultural difference?

\section{Small and Medium-enterprises (SMEs)}

In the UK, there is a legal definition of what constitutes a small business. In order to be so designated, a small business needs to fulfil two of the three criteria listed (i) not more than fifty employees; (ii) a turnover of less than $£ 6.5$ million and (iii) a balance sheet total of not more than $£ 3.26$ million [16].

The following characteristics of SMEs are proposed by [17] and used in [18]. In the main, small businesses are managed by their owners in a hands-on fashion. They are not a subsidiary of a larger company. The ownership aspect is considered a key feature and differentiator [19]. They may have a small share of the available market and are usually active in local or regional markets that are sometimes niche, which may be a complicating factor in IT offshore outsourcing.

SMEs are characterised by flat organisational structures [18] with direct, short lines of communication and they have an informal and organic culture, a characteristic which could lead to differences between the small business and an offshore outsourcing partner with a more formal culture. Another dominant characteristic is that of limited but flexible personnel with lower degree of job specification. Small companies usually have simple planning and control systems [17] but with less standardisation than their large counterparts, which 
would hinder the offshoring process. Their processes are fluid and adapt easily to change [20], which could be advantageous in the decision to engage in offshore outsourcing.

\section{SMEs and offshore IT outsourcing}

"Small and midsize organisations are beginning to find greater access to offshore resources, and offshore outsourcing is becoming a more viable alternative for all IT organisations [...] The likelihood is that these relationships will expand over time" [2].

Notwithstanding this optimistic outlook, offshore outsourcing can be a daunting prospect for a small business. Tight budgets and scarce resources have an impact and expensive teleconferencing facilities may not be an option, for instance. There is usually a shortage of management and other specialised staff. This coupled with a lack of documentation can make the challenges great for a small business [21]. There are some advantages for the small business, however. Their agility and lack of infrastructure can mean that they can move more quickly than larger more bureaucracy-rich organisations [20].

\section{RESEARCH QUESTIONS}

The research problem may be summarised by the following three questions:

1. What was the strategic planning for the small business owner/manager that led to the decision to outsource?

2. What impact does the size of the company have on the decision to engage in IT offshore outsourcing and the outcome?

3. How does a small company manage cultural differences in IT offshore outsourcing projects?

\section{TOWARDS A FRAMEWORK OF OFFSHORE IT OUTSOURCING IN SMES}

Employing Davis and Olson's revised version of Leavitt's model provides a useful starting point for formulating a framework that will assess the impact of IT offshore outsourcing on its working culture [23]. What follows is an exposition of each of the five facets of Leavitt's model in light of IT offshore outsourcing.

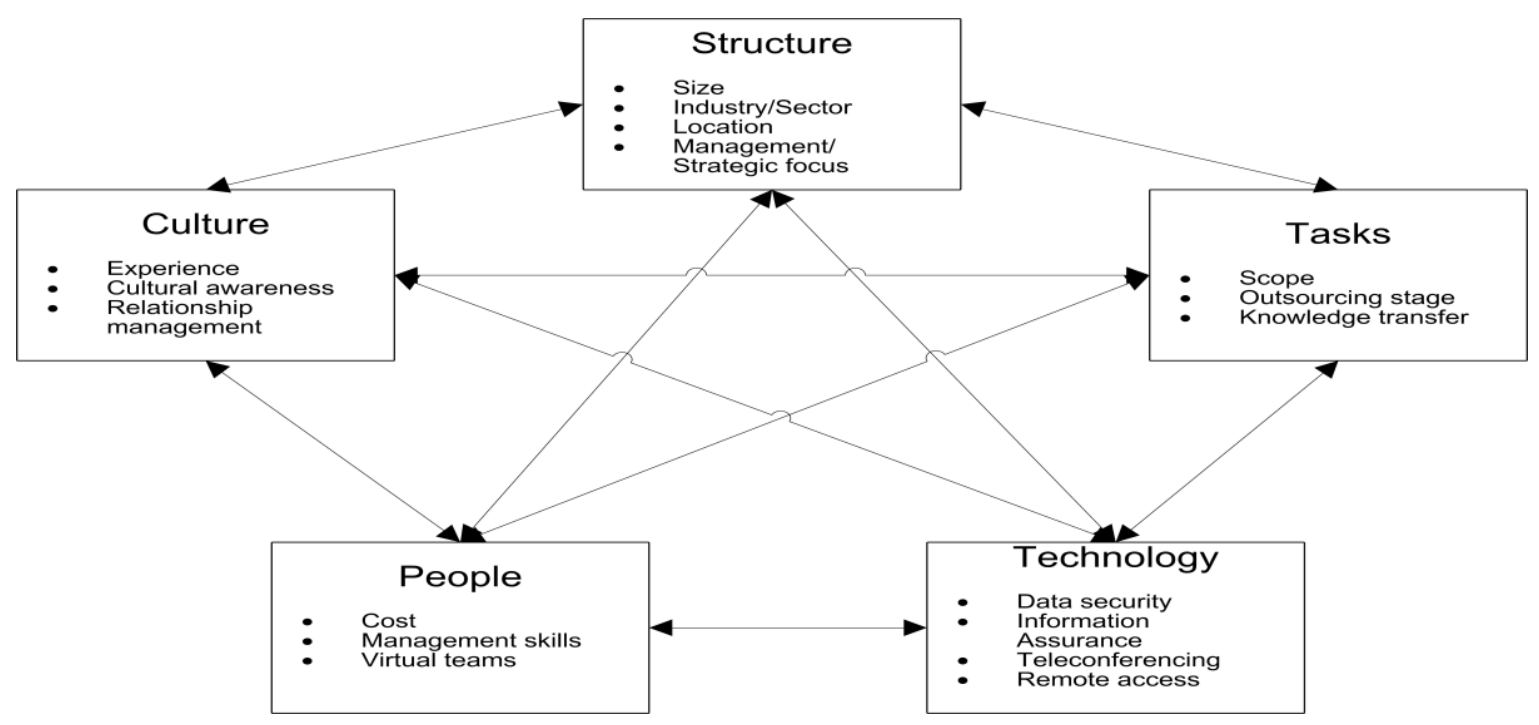

Fig. 1. IT Offshore Ooutsourcing as it applies to Leavitt

\section{A. Structure}

\section{1) Size}

Small businesses are generally considered to be more agile and less encumbered by the bureaucracy associated with larger companies, therefore "Shifting certain business processes to an overseas partner may enable SMEs to rapidly pursue emergent international opportunities" [20]. Small companies, however, can be at a disadvantage relative to larger companies engaging in IT offshore outsourcing due to their size [21], [22]. There are resource constraints such as a shortage of management staff and a lack of specialised personnel e.g. IT, finance and legal.

\section{2) Industry/sector}

It has been suggested that manufacturing, banking and finance and technology companies are most likely to engage in IT offshore outsourcing. This may imply that other industries are less likely to participate in this endeavour. However, it remains to be seen if this trend is also typical for small businesses. 


\section{3) Location}

Location may play a role in the decision to partake in IT offshore outsourcing. For example, in London, the recommended "Living Wage" is $£ 8.80$, whereas the national minimum wage is $£ 6.31$ [25], [26]. This disparity in pay and the competitiveness of the employment market in London and the Southeast may contribute to the decision to offshore, particularly for a small business whose budget may not stretch to the average pay expectations of an IT professional in this region.

\section{4) Management and strategic focus}

In [27], a written business plan is positively associated with growth for small businesses. It is of interest to obtain information on the management and strategic focus of small firms, to identify trends in strategic planning that may lead to the adoption of an offshore outsourcing strategy and whether strategic awareness and planning can lead to a more successful outcome for IT offshore outsourcing projects in SMEs.

\section{B. Task}

\section{1) Scope of activities}

It is necessary to determine what scope of task is being outsourced since "higher task complexity necessitates joint coordination and a closer more co-operative working relationship" [28]. Resource constraint in the small company may be a factor in the successful outcome of an IT offshore outsourcing project; therefore this needs to be carefully considered when deciding which IT activities to source offshore.

\section{2) Outsourcing stage}

The nature of tasks and the degree of effort required from the client organisation change depending on each stage of the IT offshore outsourcing project, therefore this information is important to capture. For example, the implementation stage of the project may require effort from each area of Leavitt's model and so put a lot of strain on scarce resources in the small company, in particular the owner/manager's time.

\section{3) Knowledge transfer}

Rottman believes that cultural understanding is key to successful knowledge transfer [8]. Cultural differences can be a significant barrier to knowledge transfer. Small businesses may not have many documented sources of information [21] which could hamper an offshore project.

\section{Technology}

\section{1) Data Security}

Data security is widely considered in the literature to be a particular issue with IT offshore outsourcing. In the main it is treated as an operational risk or problem, due to the difficulty in controlling and monitoring offshore vendors (e.g. [24] and [29]). The literature reviewed is descriptive of this issue, rather than providing a guide as to what the more common sources of data security are and how best these issues may be mitigated. Where there are solutions suggested these are quite general and focus on the cost and disruption of monitoring and audit (e.g. [30]). In the few academic studies of SMEs and IT offshore outsourcing that exist, the issue of data security is frequently omitted and when it is mentioned, the topic is not covered in any depth. This implies that data security has yet to be studied academically from the perspective of small companies, or the type of offshoring projects prevalent in this sector do not involve the offshoring of data.

\section{2) Document Assurance}

Improving documentation quality and maintenance can effect a smoother transition from in-house to offshore. Documentation will now have an audience of non-native English speakers, who are external to the client company; therefore clarity and avoidance of internal company jargon are prerequisite to successful knowledge transfer.

\section{3) Teleconferencing}

The ability to communicate remotely needs to be addressed since "communications barriers distort human-tohuman communications, even for people of similar backgrounds" [31]. There are myriad teleconferencing and messaging tools available, however many of these could prove beyond the budget of a small company.

\section{4) Remote access}

Allowing external access to systems can be beneficial and depending on the nature of the IT offshore outsourcing project, may be vital to its success. This is another area that may require investment or prove expensive for a small company [21].

\section{People}

\section{1) Management skills}

In [14] outsourcing is described as a "people business". It is necessary for the client company to pay attention to its capabilities from a management skills perspective, since as a result of IT offshore outsourcing there needs to be "a rebalancing of capabilities, activities and relationships in the management structure" [32]. This may be a particular issue for a small company, since the owner/manager may not possess these skills or have the time or budget to acquire these and this may have implications for the outcome of the project.

\section{2) Virtual teams}

Virtual Teams are defined as teams whose members are geographically dispersed and communicate with the help of technology. In order to get the best out of these teams, "cultural differences must be acknowledged and respected" [4]. It is believed that "the warmer the relationship between virtual team members [...] the greater the level of outsourcing success" [13]. Questions to ask are: does the capability to manage geographically dispersed teams exist within the client organisation? Does the capacity exist in small company management to take this on?

\section{3) Cost}

Cost reduction is almost ubiquitously cited as one of the primary motivations to engage in IT offshore outsourcing in the literature reviewed. It stands to reason, then, that the risks 
associated with these costs are very frequently discussed. For example, Reference [32] illustrates one of the central issues with cost benefit analysis: "the potential cost and risk of offshoring are not so easily measured and can go far beyond the direct cost of the project". Other research focuses on the economy of scale issues faced by SMEs, in comparison with large corporations in engaging in IT offshore outsourcing [33].

\section{E. Culture}

\section{1) Experience}

The culture of a small business is often very strong [34]. The small business engaging in IT offshore outsourcing can use this to its advantage. "Motivated people" [21] can harness IT offshore outsourcing to their advantage. Reference [15] makes a convincing case for the concept of a "negotiated culture" in "cross-regional and cross-organisational IT offshoring project teams" and rank cultural intelligence alongside "technical skills, business and functional knowledge".

\section{2) Cultural awareness}

It is believed that if the organisation engaging in IT offshore outsourcing has experienced people who are aware of cultural differences and have experience of managing them, then this will lead to a better outcome for the project by improving awareness of cultural issues and fostering an understanding of how to manage issues arising from cultural differences. Training, particularly in regard to cultural awareness, needs to be specific and not just a high level cultural overview [10]. Small businesses would be less likely to invest in such training than their larger counterparts, given the resource poverty associated with small businesses [3].

\section{3) Relationship management}

Mirani states that "offshore initiatives usually begin as transactional exchanges but end up in the relational realm" [28] and active management of cultural differences is central to the development of this relationship [13]. In a small business setting does the owner/manager have time to invest in these relationships? Similarity in size as being one of the success factors in the relationship between the case study client and the vendor and the mismatch in size between the client and the vendor may have a negative impact on this relationship. Additionally, the relationship quality can play a large role in the decision to change vendors [22].

A framework has been developed from Leavitt's model in order to investigate those factors highlighted in the literature that may facilitate or inhibit offshore IT outsourcing in a small business setting (see Table 1 below). The aim of this framework is to facilitate the discovery of answers to the principal questions posed by this paper. It provides a theoretical position from which to embark on the primary research.

TABLE I. FRAMEWORK OF PROPOSITIONS

\begin{tabular}{|l|l|c|c|c|}
\hline \multicolumn{1}{|c|}{ Classification } & \multicolumn{1}{|c|}{ Enabler/facilitator } & Inhibitor & Indeterminate \\
\hline Structure & Size & & $\mathrm{X}$ \\
\hline & Industry/Sector & $\mathrm{X}$ & \\
\hline & Location & & $\mathrm{X}$ \\
\hline Tasks & Management/Strategic Focus & & $\mathrm{X}$ \\
\hline & Scope of activities & & $\mathrm{X}$ \\
\hline & Outsourcing Stage & & \\
\hline Technology & Knowledge Transfer & & \\
\hline & Capabilities - Documentation & $\mathrm{X}$ & \\
\hline & Teleconferencing & $\mathrm{X}$ & \\
\hline People & Remote Access & $\mathrm{X}$ & \\
\hline & Capabilities - Management Skills & $\mathrm{X}$ & \\
\hline Culture & Virtual Teams & $\mathrm{X}$ & \\
\hline & Experience & $\mathrm{X}$ & \\
\hline & Awareness & $\mathrm{X}$ & \\
\hline
\end{tabular}

\section{REFERENCES}

[1] M.C. Lacity, S. Khan, A. Yan, and L.P. Willcocks, A review of the IT outsourcing empirical literature and future research directions, Journal of Information Technology, 2010, 25 (4) pp. 395 - 433
[2] Computer Economics Report, Small, midsize companies drive rise in offshore outsourcing, Computer Economics, 2009, Irvine, CA, 31 (10) pp. 1-5.

[3] J.A. Welsh and J.F. White, A small business is not a little big business. Harvard Business Review, 1981, 59(4), pp. 1-12. 
[4] N. Brooks, Understanding IT outsourcing and its potential effects on IT workers and their environment, Journal of Computer Information Systems, 2006, 46 (4), pp. 46-53.

[5] S. Manning, S. Massini, and A.Y. Lewin, A dynamic perspective on next-generation offshoring: the global sourcing of science and engineering talent, Academy of Management Perspectives, 2008, 22 (3), pp. 35-54.

[6] A.K. Pai and S. Bau, Offshore technology outsourcing: overview of management and legal issues, Business Process Management Journal, 2007, 13 (1), pp. 21-46.

[7] M. Musteen and M. Ahsan, Beyond cost: the role of intellectual capital in offshoring and innovation in young firms, Entrepreneurship: Theory and Practice, 2013, 37 (2) pp. 421-434.

[8] J.W. Rottman, Successful knowledge transfer within offshore supplier networks: a case study exploring social capital in strategic alliances, Journal of Information Technology, 2008, 23 (1), pp. 31-43.

[9] S. Kumar, A. Kwong, and M. Misra, Risk mitigation in offshoring of business operations, Journal of Manufacturing Technology Management, 2009, 20 (4) pp. 442-459.

[10] L.P. Willcocks and M.C. Lacity, The practice of outsourcing: From information systems to BPO and offshoring, 2009, Palgrave.

[11] J.K. Winkler, J. Dibbern, and A. Heinzl, The impact of cultural differences in offshore outsourcing - Case study results from GermanIndian application development projects, Information Systems Frontiers, 2008, 10 (2), pp. 243-258.

[12] M.N. Aydin, J. de Groot, and J. van Hillegersberg, Action readiness and mindset for IT offshoring, Journal of Enterprise Information Management, 2010, 23 (3) pp. 326-349.

[13] A. Gurung and E. Prater, A research framework for the impact of cultural differences on IT outsourcing, Journal of Global Information Technology Management, 2006, 9 (1) pp. 24-43.

[14] A. Plugge and M. Janssen, Managing change in IT outsourcing arrangements: an offshore service provider perspective on adaptability, Strategic Outsourcing: An International Journal, 2009, 2 (3), pp. 257274.

[15] R. Gregory, M. Prifling, and R. Beck, R., The role of cultural intelligence for the emergence of negotiated culture in IT offshore outsourcing projects, Information Technology \& People, 2009, 22 (3), pp. 223-241.

[16] Companies Act 2006, from www.legislation.gov.uk, Accessed on July 2014.

[17] Y.W. Kuan and E. Aspinwall, Characterizing knowledge management in the small business environment, Journal of Knowledge Management, 2004, 8 (3) pp. 44-61.

[18] V. Supyuenyong, N. Islam, and U. Kulkarni, Influence of SME characteristics on knowledge management processes, Journal of Enterprise Information Management, 2009, 22 (1/2), pp. 63-80.

[19] G. Beaver and C. Prince, Management, strategy and policy in the UK small business sector: a critical review, Journal of Small Business and Enterprise Development, 2004, 11 (1), pp.34-49.

[20] D. Di Gregorio, M. Musteen, and D.E. Thomas, Offshore outsourcing as a source of international competitiveness for SMEs, Journal of International Business Studies, 2009, 40 (6), pp. 969-988.

[21] E. Carmel and B. Nicholson, Small firms and offshore software outsourcing: high transaction costs and their mitigation, Journal of Global Information Management, 2005, 13 (3), pp.33-54.

[22] N.B. Moe, D. Šmite, G.K. Hanssen, and H. Barney, From offshore outsourcing to insourcing and partnerships: four failed outsourcing attempts. Empirical Software Engineering, 2014, 19(5), pp. 1225-1258.

[23] G.B. Davis and M.H. Olson, Management information systems: conceptual foundations, structure and development, second ed., 1984, New York: McGraw-Hill.

[24] V. Morabito, M. Themistocleous, and A. Serrano, A survey on integrated IS and competitive advantage, Journal of Enterprise Information Management, 2010, 23 (2), pp. 201-214.

[25] Great Britain, Department for Work and Pensions, National minimum wage rates, Available from https://www.gov.uk/national-minimumwage-rates, 2013, Accessed on 16 June 2014.
[26] Greater London Authority, A fairer London: the 2013 living wage in London, London, Greater London Authority, 2013 November, Available from: https://www.london.gov.uk/sites/default/files/living-wage2013.pdf, Accessed on 16 June 2014.

[27] R.A. Blackburn, M. Hart, and T. Wainwright, Small business performance: business, strategy and owner-manager characteristics, Journal of Small Business and Enterprise Development, 2013, 20 (1), pp. 8-27.

[28] R. Mirani, Client-vendor relationships in offshore applications development: an evolutionary framework, Information Resources Management Journal, 2006, 19 (4), pp. 72-86.

[29] K. Knapp, S. Sharma, and K. King, Macro-economic and social impacts of offshore outsourcing of information technology: practitioner and academic perspectives, International Journal of E-Business Research, 2007, 3 (4), pp. 112-123,125-132.

[30] C.J. Robertson, A. Lamin, and G. Livanis, Stakeholder perceptions of offshoring and outsourcing: the role of embedded issues, Journal of Business Ethics, 2010, 95 (2), pp. 167-189.

[31] W.O. Jones, Outsourcing in China: opportunities, challenges and lessons learned, Strategic Outsourcing: An International Journal, 2009, 2 (2), pp. 187-203.

[32] J. Dedrick, E. Carmel, and K.L. Kraemer, A dynamic model of offshore software development, Journal of Information Technology, 2011, 26 (1), pp. $1-15$.

[33] J. Hätönen and M. Ruokonen, Revising marketing strategies for supplier selection criteria: small firm approach from the information and communications industry, Journal of Business \& Industrial Marketing, 2010, 25 (2), pp. 159-167.

[34] J.H. Gray, I.L. Densten, and J.C. Sarros, Size matters: organisational culture in small, medium and large australian organisations, Journal of Small Business and Entrepreneurship, 2003, (17) 1, pp. 31-46. 